\title{
AC 2012-4224: AN INTERDISCIPLINARY PROGRAM FOR EDUCATION IN HYBRID AND ELECTRIC DRIVE VEHICLE ENGINEERING
}

\author{
Dr. Wayne Weaver, Michigan Technological University
}

Wayne Weaver received a B.S. degree in electrical engineering and a B.S. in mechanical engineering from GMI Engineering \& Management Institute in 1997, and M.S. and Ph.D. degrees in electrical engineering from the University of Illinois, Urbana-Champaign. He was a Research and Design Engineer at Caterpillar, Inc., Peoria, Ill., from 1997 to 2003. From 2006-2008, he also worked as a researcher at the U.S. Army Corp of Engineers, Engineering Research and Development Center (ERDC), Construction Engineering Research Lab (CERL), in Champaign, Ill., on distributed and renewable energy technology research. Weaver is a registered Professional Engineer in the state of Illinois. He is currently an Assistant Professor in the Department of Electrical Engineering at Michigan Technological University.

\section{Jeremy John Worm P.E., Michigan Technological University}

Jeremy John Worm is the Director of the Mobile Sustainable Transportation Laboratory at Michigan Tech and a Research Engineer in the Advanced Power Systems Research Center. Worm teaches several courses pertaining to hybrid vehicles, and IC engines. In addition to teaching, his research interests include internal combustion engines, alternative fuels, and vehicle hybridization. Prior to coming to Michigan Tech, Worm was a Lead Engine Development Engineer at General Motors, working on high efficiency engines in hybrid electric vehicle applications.

Dr. Jeffrey D. Naber, Michigan Technological University

Dr. Leonard J. Bohmann, Michigan Technological University

Leonard J. Bohmann received his B.S. in electrical engineering from the University of Dayton in 1983, and his M.S. and Ph.D. in electrical engineering from the University of Wisconsin in 1986 and 1989, respectively. After graduating, he accepted a faculty position at Michigan Tech in the Department of Electrical and Computer Engineering. Bohmann was appointed Interim Chair of the department for the 2007-08 academic year, and in 2007, he was also appointed to his present position: Associate Dean for Academic Affairs within the College of Engineering.He is an ASEE member, and participates in the Electrical and Computer Engineering, Energy Conversion and Conservation, Computers in Education, and Educational Research and Methods divisions. He is the Past Chair of the Electrical and Computer Engineering Division.

Dr. John E. Beard

Dr. Carl L. Anderson, Michigan Technological University

Carl L. Anderson is a professor in the Mechanical Engineering-Engineering Mechanics Department and Associate Dean for Research and Graduate Programs in the College of Engineering at Michigan Technological University. He is the Principal Investigator for the Department of Energy project: An Interdisciplinary Program for Education and Outreach in Transportation Electrification. He serves on the governing board of the Michigan Academy for Green Mobility Alliance (MAGMA) that works with the state of Michigan to promote hybrid electric vehicle engineering education.

\section{Dr. Bo Chen, Michigan Technological University}

Bo Chen received the Ph.D. degree in mechanical engineering from the University of California, Davis, in 2005. She conducts interdisciplinary researches in the areas of agent-based intelligent systems, pattern recognition, engine and hybrid vehicle powertrain control, and real-time monitoring systems. Chen has authored or co-authored more than 60 peer-reviewed journal and conference papers. She received the Best Paper Award at 2008 IEEE/ASME International Conference on Mechatronic and Embedded Systems and Applications. Chen has been an active member of the ASME and IEEE. She is the Vice Chair of the ASME Technical Committee on Mechatronic and Embedded Systems and Applications (MESA) and the Program Chair of the 2012 IEEE/ASME International Conference on Mechatronic and Embedded Systems and Applications.

Dr. Jason M. Keith, Mississippi State University

(C)American Society for Engineering Education, 2012 
Jason Keith is a professor and Director of the Dave C. Swalm School of Chemical Engineering at Mississippi State University. He is also the holder of the Earnest W. Deavenport, Jr., Chair. Prior to joining Mississippi State, he was employed at Michigan Technological University. Keith's research and teaching interests are in the energy and emissions areas. Keith was the 2008 recipient of the Raymond W. Fahien Award from the Chemical Engineering Division of ASEE for educational scholarship and teaching effectiveness. 


\title{
An Interdisciplinary Program for Education in Hybrid \& Electric Drive Vehicle Engineering
}

\begin{abstract}
The automotive industry is in a transformation towards powertrain electrification, requiring automotive engineers to develop and integrate technologies from multiple disciplines. We have developed a new interdisciplinary master of engineering degree program and graduate and undergraduate certificates in Advanced Hybrid Electric Drive Vehicle Engineering. The vehicle level aspects of the program include vehicle requirements, integration of propulsion technologies, safety, diagnostics, control and calibration. We and our industrial partners see these as critical limiting factors in the development and production of advanced electric transportation. Additionally, the effort leverages the existing distance learning program in electric power. The result is an interdisciplinary program that meets the needs of the transportation and electric power industries and provides students with a unique skill set to accelerate the advancement and development of electric drive vehicles.

The education program delivers courses to on-campus and distance learning students for the Hybrid Electric Drive Vehicle Engineering Undergraduate and Graduate Certificates. Graduate students are able to continue on for their masters or PhD degrees in their respective departments or select an interdisciplinary master's of engineering degree. This degree is designed to prepare students to work in industry or to educate those already working. Our distance learning students come from both the transportation and electric power industries. We seek guidance from these industries to ensure that the program meets the needs of their work force with the course contents reviewed by topical industry experts. This education program will provide a supply of engineers to a significant and sustainable US job base.
\end{abstract}

\section{Introduction}

Development of a wide array of electrified vehicle powertrains has resulted in a significant shift in the automotive industry's needs for engineers experienced in multiple disciplines. This has resulted in the need for retraining the existing work force along with developing engineers with a broader knowledge base to tackle integration and optimization work in these electrified vehicles. To meet the challenges of both incumbent and transitional workers while simultaneously meeting the needs for the future workforce, Michigan Technological University has teamed with industry, state and national government agencies, and non-profit organizations to develop and deliver a curriculum in electrified vehicles. The University has a long tradition of educating engineers for both the automotive and the electric power industries, and was recently tied for first place in Edmunds list of the top ten Automotive Colleges and Universities in the U.S ${ }^{1}$. The program began with a single course in Advanced Propulsion for Hybrid Vehicles and now, with funding from the Department of Energy (DOE), has developed into an entire curriculum in Hybrid Electric Drive Vehicles with certificates at the undergraduate and graduate levels and a Master of Engineering Degree. To ensure that distance learning students get significant hands-on laboratory opportunities a Mobile Laboratory has been constructed on a 53 foot trailer that will enable laboratory courses to be offered around the country. 


\section{Curriculum Overview}

The corner stone of hybrid vehicle program are two new interdisciplinary courses, the senior level Introduction to Propulsion Systems for Electric Drive Vehicles and the graduate level Advanced Propulsions Systems for Electric Drive Vehicles. The undergraduate certificate is built around the introductory course and the graduate certificate is centered on the advanced course. Most of the remaining coursework is in existing classes that have modified sections to directly address material related to hybrid electric vehicles (HEVs). Certificate students are able to continue on for their masters or $\mathrm{PhD}$ degrees in their respective departments or select an interdisciplinary master's of engineering degree which is focused on preparing students to work in and training those already in industry. This program leverages and links the automotive systems, engines, and controls expertise in the Mechanical Engineering Department with the electric power, electric machines and power electronics expertise in the Electrical Engineering Department.

Michigan Technological University is a recognized leader in conventional and hybrid vehicle education programs. The Mechanical Engineering Department has provided specialized distance learning programs for General Motors (GM), and other OEM's, dating back to the mid 1990's. Over $500 \mathrm{GM}$ employees have taken courses, earning both certificates and degrees. In addition, Michigan Technological University has competed in in US Department of Energy (DOE) HEV student competitions since 1995. On average 23-24 students have participated each year with over half of the graduates joining the auto industry in HEV related fields. In the past decade, DOE and the hybrid vehicle competition sponsors delivered technical workshops and seminars for the vehicle teams on hybrid related issues such as software in the loop (SIL), hardware in the loop (HIL), electric machines, model based design, hybrid control strategies, etc ${ }^{2}$. Our program covers these topics in a far greater depth than is possible at a workshop and will be available to the engineering community through our distance learning option.

\section{Master of Engineering Degree}

Michigan Technological University offers and interdisciplinary master of engineering program that focuses on preparing students to work in industry and to train those already in industry. This Master of Engineering provides advanced knowledge and hands-on laboratories in the design, analysis, control, calibration, and operating characteristics of HEVs. The technologies required to achieve transportation electrification include clean and efficient internal combustion engines and electric machines, as well as emerging technologies for advanced batteries, fuel cells, and the recharging and supporting infrastructure required for each technology. The 30 course credit program of study is flexible and is designed by the student with committee approval with an expected completion in 1 year.

\section{Certificate Programs}

Michigan Technological University also offers undergraduate and graduate certificates in Advanced Electric Drive Vehicle Engineering with the graduate certificate focused on distance learning for engineers in industry. Both certificates are interdisciplinary with courses from Material Science, Mechanical, Electrical, and Chemical Engineering. The required and elective courses for the undergraduate certificate are shown in Table I and Table II respectively. Included in the undergraduate certificate are credits from the Michigan Technological University 
Enterprise program, which is an alternative to the traditional capstone senior design course. The Graduate Certificate in Electric Drive Vehicle Engineering is related to the Certificate in Hybrid Electric Drive Vehicle Engineering at the undergraduate level. The curriculum for the graduate certificate is shown in Table III and Table IV.

TABLE I: ReQuiRED COURSES For UNDERGRADUATE CERTIFICATE (10 CREDITS)

\begin{tabular}{|l|l|c|}
\hline \multicolumn{1}{|c|}{ Course } & \multicolumn{1}{|c|}{ Description } & Credits \\
\hline EE/ME 4295 & Introduction Propulsion Systems for Electric Drive Vehicles & 3 \\
\hline ME 4200 & Principles of Energy Conversion & 3 \\
\hline EE 3221 & Intro to Motor Drives & 4 \\
\hline
\end{tabular}

TABLE II: ELECTIVES COURSES For UNDERGRADUATE CERTIFICATE (6 CREDITS)

\begin{tabular}{|c|c|c|c|c|c|}
\hline Course & Description & Credits & Course & $\begin{array}{c}\text { Description } \\
\end{array}$ & Credits \\
\hline EE/ME 4296 & $\begin{array}{l}\text { Introduction to Propulsion Systems } \\
\text { for Electric Drive Vehicles } \\
\text { Laboratory }\end{array}$ & 1 & ME 4700 & Dynamic Systems \& Controls & 4 \\
\hline CM 3230 & $\begin{array}{l}\text { Thermodynamics for Chemical } \\
\text { Engineers }\end{array}$ & 3 & MY 3100 & Materials Processing & 1 \\
\hline EE 3120 & Electric Energy Systems & 3 & \multicolumn{3}{|c|}{$\begin{array}{l}\text { Maximum of } 3 \text { credits of the following and requires } \\
\text { certificate advisor approval: }\end{array}$} \\
\hline EE 4227 & Power Electronics & 3 & ENT 3950 & Enterprise Project Work III & 1 \\
\hline EE 4261 & Classical Control Systems & 3 & ENT 3960 & Enterprise Project Work IV & 1 \\
\hline EE4901/4910 & EE Design Project I/II & $1 / 3$ & ENT 4950 & Enterprise Project Work V & 2 \\
\hline ME 4901/4911 & ME Senior Capstone Design I/II & $2 / 2$ & ENT 4960 & Enterprise Project Work VI & 2 \\
\hline ENG 3200 & Thermodynamics/Fluid Mechanics & 3 & ENT 4951 & Enterprise Project Work VII & 1 \\
\hline
\end{tabular}

\begin{tabular}{|c|c|c|}
\hline ME 4220 & Intro to IC Engines & 3 \\
\hline
\end{tabular}

TABLE III: REQUiRED COURSES For GRADUATE CERTIFICATE (9 CREDITS)

\begin{tabular}{|l|l|c|}
\hline \multicolumn{1}{|c|}{ Course } & \multicolumn{1}{c|}{ Description } & Credits \\
\hline EE/ME 5295 & Advanced to Propulsion Systems for Electric Drive Vehicles & 3 \\
\hline And any two of the following: & 3 \\
\hline EE/ME 4295 & Introduction Propulsion Systems for Electric Drive Vehicles & 3 \\
\hline MY/CM 5760 & Vehicle Battery Cells and Systems & 3 \\
\hline EE 4227 & Power Electronics & 3 \\
\hline EE 5221 & Advanced Electrical Machines & 3 \\
\hline MEEM 5450 & Vehicle Dynamics & \\
\hline
\end{tabular}

TABLE IV: Electives COURSES For GRAdUATE CERTIFICATE (6 CREDITS)

\begin{tabular}{|c|c|c|c|c|c|}
\hline Course & Description & Credits & Course & Description & Credits \\
\hline EE/ME 4296 & $\begin{array}{l}\text { Introduction to Propulsion Systems } \\
\text { for Electric Drive Vehicles } \\
\text { Laboratory }\end{array}$ & 1 & ME 5700 & $\begin{array}{l}\text { Dynamic Measurement and Signal } \\
\text { Analysis }\end{array}$ & 3 \\
\hline EE/ME 5296 & $\begin{array}{l}\text { Advanced Propulsion Systems for } \\
\text { Electric Drive Vehicles Laboratory }\end{array}$ & 1 & ME 5715 & Linear Systems & 3 \\
\hline EE 5200 & $\begin{array}{l}\text { Advanced Methods in Power } \\
\text { Systems }\end{array}$ & 3 & $\begin{array}{l}\text { ME } \\
4260 / 5220\end{array}$ & Fuel Cell Technology & 3 \\
\hline EE 3120 & Electric Energy Systems, ME Only & 3 & $\begin{array}{l}\mathrm{EE} / \mathrm{ME} \\
4750 / 5750\end{array}$ & $\begin{array}{lll}\begin{array}{l}\text { Distributed } \\
\text { Systems }\end{array} & \text { Embedded } & \text { Control } \\
\end{array}$ & 3 \\
\hline EE 4221 & Power System Analysis 1 & 3 & MY 4165 & $\begin{array}{lll}\text { Corrosion and } & \text { Environmental } \\
\text { Effects } & & \end{array}$ & 3 \\
\hline EE 4222 & Power System Analysis 2 & 3 & MY 5100 & Thermodynamics and Kinetics I & 3 \\
\hline EE 5223 & Power System Protection & 3 & MY 5110 & Thermodynamics and Kinetics II & 3 \\
\hline EE 5230 & Power System Operations & 3 & MY 5410 & Materials for Energy Applications & 3 \\
\hline EE 5290 & Selected Topics in Power Systems & 3 & $\begin{array}{l}\mathrm{CM} / \text { Ent } \\
3974\end{array}$ & Fuel Cell Fundamentals & 1 \\
\hline ME 4220 & IC Engines 1 & 3 & $\begin{array}{l}\mathrm{CM} / \text { Ent } \\
3977\end{array}$ & $\begin{array}{l}\text { Fundamentals of Hydrogen as an } \\
\text { Energy Carrier }\end{array}$ & 1 \\
\hline ME 5220 & IC Engines 2 & 3 & $\begin{array}{l}\mathrm{CM} / \text { Ent } \\
3978\end{array}$ & Hydrogen Measurements Laboratory & 1 \\
\hline ME 5680 & Optimization & 3 & & & \\
\hline
\end{tabular}

EE-Electrical and Computer Engineering, ME-Mechanical Engineering,

MY - Materials Science and Engineering, CM - Chemical Engineering, Ent-Enterprise

Total of 15 credits are required for the certificate. Up to 6 credits of 3000 and 4000 level courses are allowed. 


\section{Distance Learning Programs}

The distance learning component of the Master of Engineering and Certificate programs in Hybrid Electric Drive Vehicle Engineering is modeled on the successful online Master of Science degree in Electrical Engineering with certificates in advanced electric power engineering. These certificates and degree programs were developed to meet the growing need for electric power engineers in the electric energy industry, and were designed in collaboration with numerous electric utilities such as American Electric Power. The distance MSEE program started in 2000 and the certificates in electric power were started in 2008. Approximately 40 students have completed these programs. The electric utility industry is now beginning to prepare their workforce to engineer the next generation of power infrastructure for the foreseen influx of electric vehicles across the grid. To this end, modifications to the electric power curriculum include inclusion of distributed energy resources and electric vehicles as loads in the smartgrid ${ }^{3}$.

\section{Laboratory Facilities}

A central feature of the HEV program is a Mobile Hybrid Electric Drive Vehicle Educational Laboratory. The impetus for creating a mobile laboratory is twofold. First, by creating a mobile platform, the lab hardware can be transported to large metropolitan regions where the highest density of enrolled distance learning students exist, thus enabling significantly greater participation from the distance learning students in the laboratory courses. Secondly, this mobile lab can also be taken to various K-12 schools and community events, and utilized as a demonstration and education unit in the outreach events. The primary piece of equipment is a 53 foot semi-tractor trailer which contains a class room, four universal learning stations for bench top experiments, and two test cells for complete powertrain Hardware-in-the-Loop (HIL) testing. Additional lab items include a portable vehicle chassis dynamometer, three production representative HEV's, and a Configurable Hybrid Electric Vehicle (CHEV).

Figure 1 depicts the workflow through the mobile lab for a portion of the course work that the students can take. Students will start by building Matlab Simulink based models of an HEV. They will use the lab's test cells to characterize the models powertrain components, and integrate that data into the Simulink models for improved accuracy. Likewise they will use the vehicles to collect systems level data for usage in the models. As the model approaches completion, the students will evaluate their model through a bench-top ECU based HIL station before performing final model evaluation in the test cells, and using the vehicles.

\section{Core Courses}

\section{EE/MEEM 4295 Introduction to Propulsion Systems for Electric Drive Vehicles}

The introductory course in HEV's is EE/MEEM 4295 where the concepts of hybrid and electric drive vehicles are introduced with the main focus on the development of mathematical models of hybrid powertrains. Students are introduced to HEV/EV history, hybrid architecture for series and parallel systems, vehicle characteristics, starting equations of motion, vehicle performance (need for electrification), introduction to model based design in Simulink, electric machines, electric drive systems, regenerative braking, power electronics, battery models as RC circuits, 
introduction to drive cycles and driver controls, effects of road conditions and energy efficiency over a specified drive cycle.

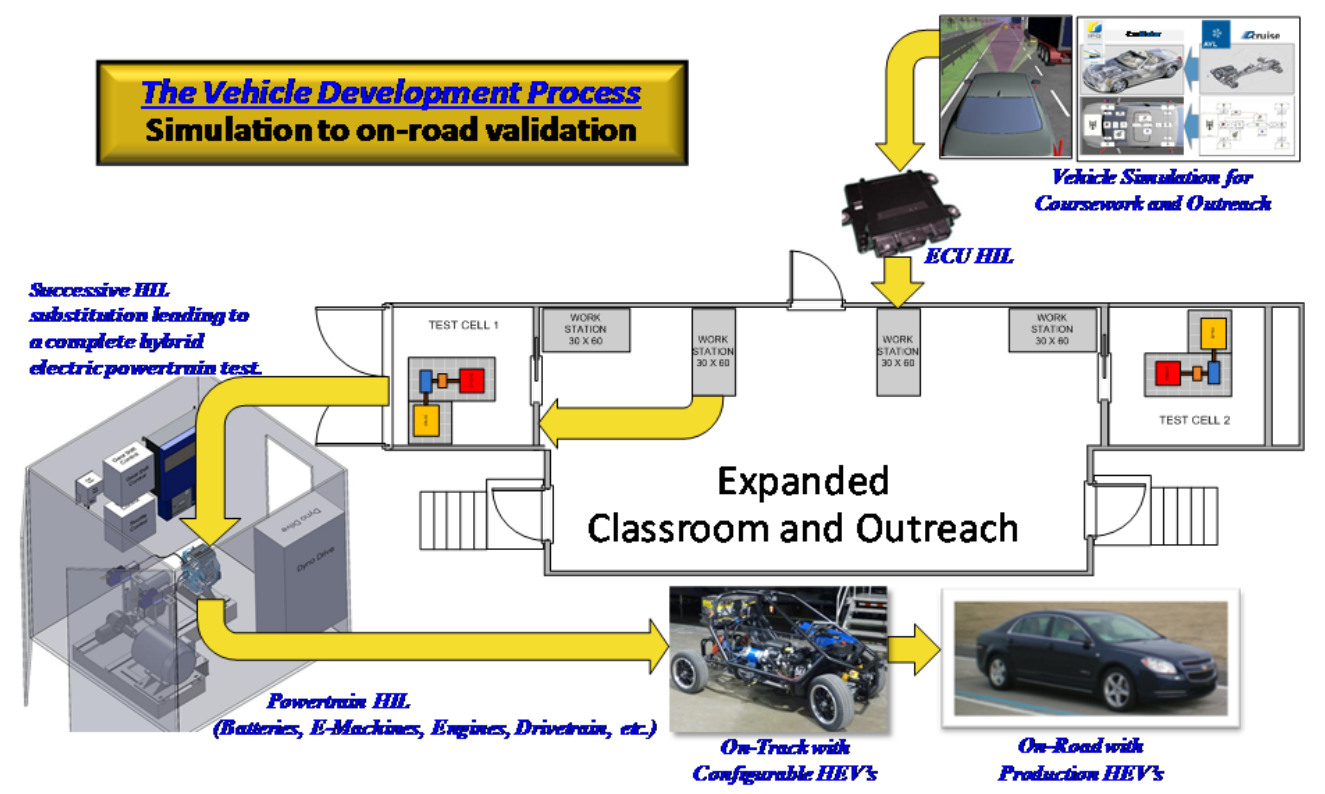

Figure 1. Floor plan, equipment layout and workflow of 53 foot tractor trailer mobile laboratory.

The assignments were designed to culminate with a complete hybrid vehicle model (HVM) in Simulink with a driver controller (PID), IC engine, electric machine, battery (FreedomCar model), finite ratio transmission and longitudinal vehicle dynamics subsystems linked to a drive cycle. The students developed their own HVM, including diagnostic subsystems using standard Simulink building blocks. Their final HVM included torque blending between the IC engine and E-Motor, engine-stop, transmission gear selection based on ICE torque request and fuel usage in each available gear, regeneration during braking and over-all fuel economy for a given drive cycle. The IC engine model contained the torque, fuel flow rate and engine speed from a current production engine.

Highly sophisticated HEV simulation models such as ADVISOR, PSAT, Autonomie, as well as many others are available and provide excellent drive cycle simulations results. There is a pedogical reason for having the students develop their own HVM in place of the "commercial" software that is available. Developing their own model enables the students to concentrate on understanding the fundamentals rather than leaning "icon" location usage and software package peculiarities.

\section{EE/MEEM 4296/5296 Intro and Advanced Propulsion Systems for Electric Drive Vehicles Laboratory}

There are currently two courses taught from the mobile lab, with more in development. The first course "Introduction to Propulsion Systems for Hybrid Electric Drive Vehicles" focuses on the subsystems within a modern HEV, with emphasis on energy conversions and the thermodynamics based energy balance around the vehicle. In this course the students use the laboratory facilities to characterize specific HEV subsystems, while learning basic operational 
principals of the systems. Examples include; measurement of engine fuel consumption surfaces, determination of motor torque constants and efficiency, development of battery state-of-charge (SOC) versus capacity relationships, approximation of vehicle drag and rolling resistance including coast down experiments, and measurement of various vehicle parameters including mass and frontal area. Much of this data is collected with the subsystems from the CHEV. The course also teaches students HEV safety practices and utilizes a defined drive cycle on public roads to demonstrate basic experimental principals. Figure 2 shows a student checking for the presence of high voltage during an HEV safety lab.

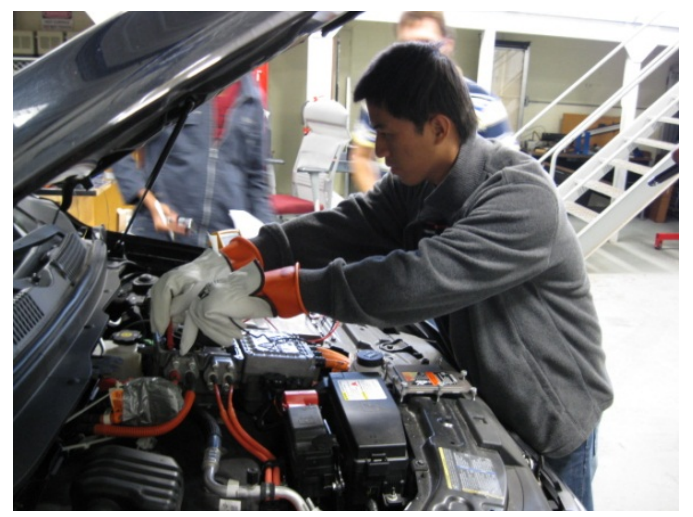

Figure 2. A student testing for the presence of high voltage in the Introduction to Propulsion Systems for Hybrid Electric Drive Vehicles" lab course.

The first course is a prerequisite for the second course "Advanced Propulsion Systems for Hybrid Electric Drive Vehicles". In the advanced course, students utilize the subsystems data they collected in the introductory course to calibrate their previously developed vehicle simulation models. In doing so, their models begin to accurately reflect the performance of the CHEV. With their models calibrated, they conduct validation experiments using the powertrain test cells and vehicle. Figure 3 shows students preparing to collect drive cycle data on the CHEV for model validation.

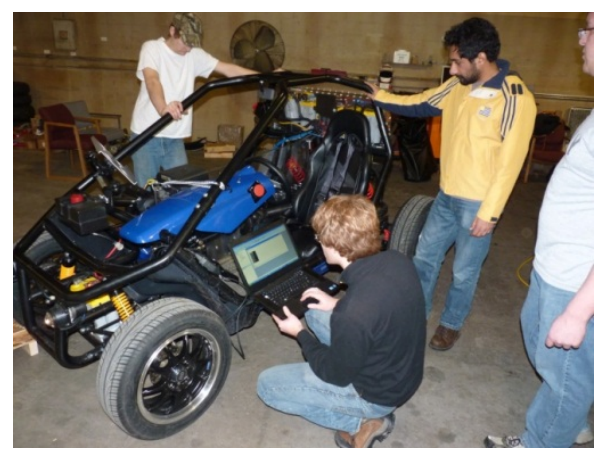

Figure 3. Students preparing for data collection from a CHEV to be used for model validation.

The final project in the course requires students to work in teams to optimize the performance of the CHEV. The students must take many considerations into account including fuel consumption, acceleration, top speed, drivability, charge sustainability, and cost. Students have a multitude of hardware and software options they can change to affect the vehicle. Examples include mass, frontal area, various gear ratios, and with software can develop improved 
regenerative braking, torque blending, and engine off algorithms and calibrations. The students use their calibrated models to conduct preliminary sorting analysis to determine performance trends, and develop a promising set of hardware and software changes. Next the students will be given time to test their hardware and software strategies by operating the Powertrain HIL test cells over the vehicles drive cycles. This will allow the students the opportunity to further refine their models if needed. Students are also given time with the CHEV for testing of their hardware and software solutions. Using the Powertrain HIL test cells and CHEV they can iterate as needed to arrive at a final solution. Final results are presented by the teams of students to a panel of subject matter experts, and course points are awarded based on a multitude of factors including how well the teams' vehicle performed in each of the target areas. Figure 4 shows the student team results in the fuel economy category from the spring 2011 final project.

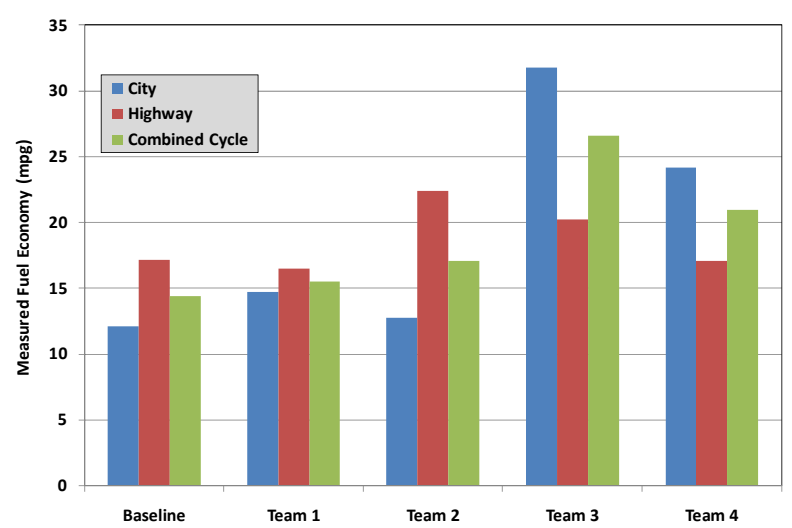

Figure 4. Fuel economy results from the final project in the Advanced Propulsion Systems for Hybrid Electric Drive Vehicles Course.

\section{EE/ME 4750/5750 Distributed Embedded Control Systems}

Automotive embedded control systems are introduced in the course of "Distributed Embedded Control Systems." The course covers topics such as embedded system architecture, model-based embedded system design, electronic control unit (ECU), sensors and actuators, real-time control, and communication protocols. The course employs industrial standard rapid prototype system, Woodward's MotoTron Control Solutions, for the design and calibration of automotive embedded control systems. Several laboratories related to the lectures have also been developed to allow students developing vehicle control strategies in MotoHawk/Simulink/Stateflow. The developed model-based controllers can be validated directly in production-level engine control modules (ECMs) with real-time calibration software MotoTune. Multiple controllers can communicate with each other using controller area network (CAN) communication protocol.

The final project of the "Distributed Embedded Control Systems" is designed to guide students through the process of developing a control system for a reconfigurable hybrid vehicle. The control system consists of eight sub-modules to determine vehicle driving mode, engine/E-motor blend factors, and the sequence of the engine throttle stepper motor coil signals as shown in Figure 5. First, students design control modules based on defined control logics. Then, these control modules are simulated in the MotoHawk/Simulink to test the input and output signals of each module. Once the design of control modules is completed, the application code for programming into the ECM is generated using Matlab Real-Time Workshop, Real-Time 
Workshop Embedded Coder, and Stateflow Coder. Finally, the entire embedded control system is validated in the hardware-in-the-loop test.

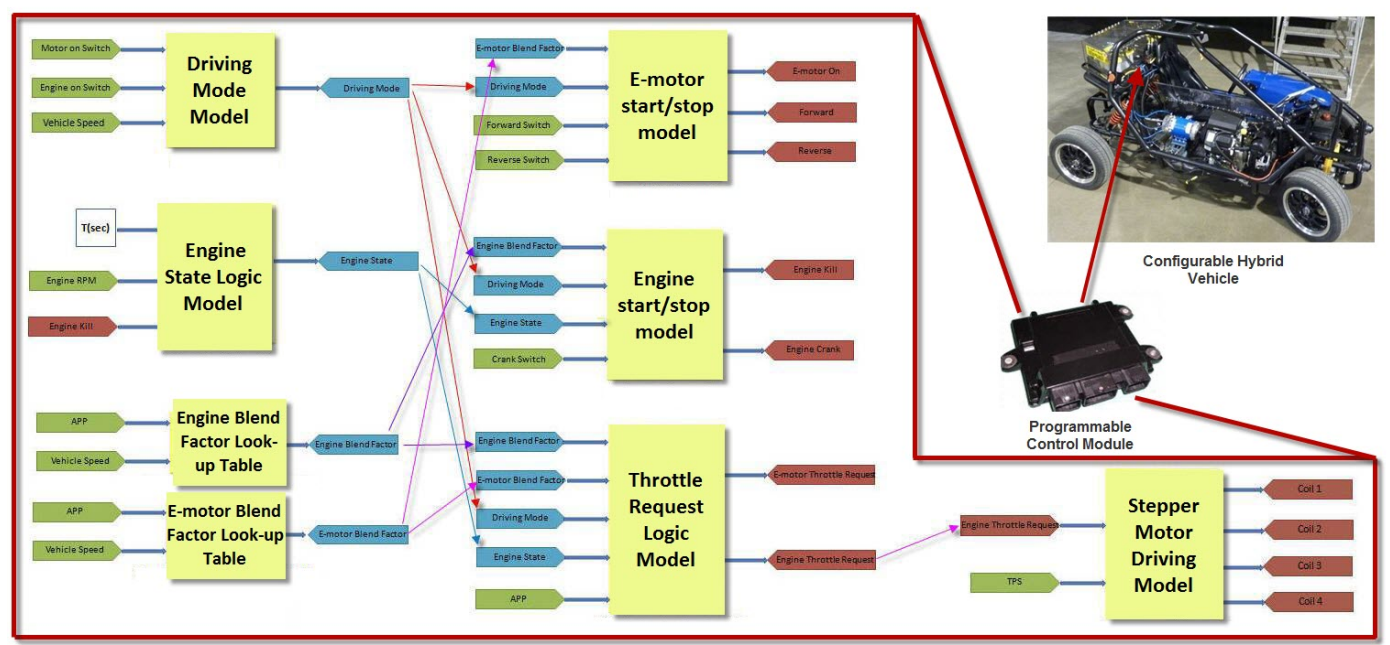

Figure 5. Developing a hybrid vehicle control system in the final project of the "Distributed Embedded Control Systems."

\section{MY/CM 5760 Vehicle Battery Cells and Systems}

The behavior and application of batteries are examined by introducing concepts from thermodynamics, materials science, transport processes and equivalent circuits. The non-ideal power source behavior of rechargeable batteries in applications will be treated using electrolyte: electrode transport and electrode materials chemistry.

Although there is no laboratory in this course, virtual laboratory activities are carried out in the latter third of the semester using a battery simulation tool. This battery component of this tool will be based on a multiple component equivalent circuit with resistances and capacitances dependent upon electrode structure and chemistry (thickness, porosity, conductivity, particle size, cycle history, anode/cathode capacity matching, electrolyte salt concentration...). The equivalent circuit model is being developed to correspond to porous electrode behavior. This can be a realistic, low computational cost battery model capable of fitting into the overall certificate program development activities involving HEV/EV system simulations. At present, the battery simulation tool is using the numerical solver/matrix algebra solver in MathCad.

\section{EE 4227/4228 Power Electronics Lecture and Lab}

This course focuses on the fundamental of circuits for solid state electrical energy processing including discussions of power electronics as a vital enabler of future energy systems. Major topics include switching converter principles, harmonics, pulse-width modulation, phase control, and phase modulation, dc-dc, ac-dc, and dc-ac, power converters, high-performance power supply circuits, power components, including capacitors, magnetic components and power semiconductor switching devices.

The one credit laboratory course on power electronics (EE4228) focuses on the design construction and troubleshooting aspects of power electronic circuits. For approximately one 
third of the semester students use pre-made converter circuits and carries out analysis and develops controls algorithms using dSPACE rapid prototyping systems. In the next third of the course students build various converters from piece-parts including the power stage, pulse width modulation (PWM) and gate drive circuits. In the last third of the course, students are given individual design projects where they design, build and demonstrate a converter circuit built to meet unique specifications and requirements.

\section{EE 5221 Advanced Electric Machinery}

This course centers on the areas of advanced electro-mechanics of rotating and linear machines. Topics included dynamic analysis of machines, reference frame transformations, reduced order models, models of mechanical loads, power electric drives for motors, and digital simulation of machines and electric drive systems. Particular emphasis in the course is placed on advanced control techniques of induction and permanent magnet machines for propulsion systems.

\section{EE/MEEM 5295 Advanced Propulsion Systems for Electric Drive Vehicles}

The capstone course for the graduate certificate is Advanced Propulsion for Hybrid Vehicles. This course covers advanced vehicle propulsion systems within a hybrid electric vehicle context with a focus on application, integration, testing, and development of vehicle systems. It is a three credit hour level course with material developed and presented by faculty from multiple departments and industry experts. There is no textbook, reading and study materials come from technical papers and extracts from other technical sources that are compiled by the instructors. Course topics and learning objectives include the following:

- Vehicle and powertrain systems requirements, regulations, design, implementation, calibration, and validation and verification,

- Energy storage, conversion and power systems from the perspective of HEV propulsion systems,

- Model based design, simulation, control, and diagnostics utilizing Matlab/Simulink

- HEV high voltage sub-systems including electrical drive systems, electric machines, batteries,

- Batteries in application to HEV's including, chemistries, energy densities, costs, rate dependent charge and discharge characteristics and their design, analysis, models, simulation, and control,

- Vehicle dynamics coupled with HEV propulsion systems, simulation, control and calibration.

Applying active learning techniques, material from literature including conference and journal papers are discussed weekly and analysis tools developed in the course are applied to further analyze results and claims. Requirements including regulations for current and future corporate average fuel economy (CAFE) and $\mathrm{CO} 2$ regulations are studied and analyzed to underscore the need for rapid advanced advancement of technology integration in the light duty fleets. Student teams a scenario of technology advances for a hypothetical OEM from a baseline of four vehicle types to meet the US CAFE 2016, 2020 CAFE 4\%, and 2025 CAFE 4\% targets for this fleet. Data from existing literature including the National Academy of Science 2010 study of "Assessment of Technologies for Improving Light Duty Vehicle Fuel Economy", Team 
portfolios are discussed based on engineering complexity and other factors. This is carried through in a follow-on study to assess back period for technologies to determine customer acceptance.

Throughout the class, content on the primary powertrain subsystems is developed for incorporation and development of a vehicle dynamics model which is used in model based design study for assessment of technologies, component sizing, control and calibration to assess vehicle performance factors including acceleration and fuel consumption. The course culminates in a group project, which can take one of three forms:

Option 1: Design an HEV including powertrain architecture and components and develop a model for the powertrain and integrate it into a vehicle model. Quantify its performance via drive-cycle simulation and analysis. Compare to HEVs in the market place.

Option 2: Develop a simulation matching an existing HEV. Compile technical data on the vehicle attributes, parameters, and performance characteristics. Tune the model to match the performance characteristics. Quantify its performance via drive-cycle analysis. Compare to data available on the HEV.

Option 3: Develop a high order accurate model of a HEV subsystem and integrate it into a model for vehicle cycle simulation. Verify the subsystem model by developing an independent test procedure and compare to available known solution cases. Validate the subsystem model by testing within the vehicle model.

A vehicle model is provided as a baseline. Throughout the process verification and validation methods are stress and required. Final projects for the last semester's project included: modeling a 2009 Toyota Prius, hybridize the base Chevy Malibu, model and develop a F1 kinetic energy recovery system (KERS) and validate on a F1 track through vehicle simulation, and development of an enhanced motor drive and electric machine component model.

\section{Education and Outreach Gaming Software}

As part of the outreach program, a stand-alone interactive software and game package is under development to serve as an educational tool for electric vehicle technology and operation. A student group is developing the 3D game first person driving game where players can design and test HEV's and will provide feedback to help create more economical and safer driving habits. The program will be used in tandem with a full presentation about hybrid vehicles. The program is specifically targeted at 8 th -12 th grade students, general public, community college, and nondegree seeking undergraduates to raise awareness for hybrid vehicle technologies.

\section{Project Evaluation}

Project evaluation so far has included both formative and summative efforts. Both quantitative and qualitative methods were used to evaluate the project's success at meeting its designed objectives. For the core courses of the project, permission was granted by the Michigan Technological University Institutional Review Board for a survey to the students on both technical content and teaching methods of these courses. The survey consists of three categories of questions: general questions (4 questions), course-based questions (6 questions), and program- 
based questions (6 questions). The course survey was conducted using Survey Monkey. To accurately evaluate course content in a blended learning environment, additional survey questions were designed for the distance learning students to assess the impact that delivery mechanism may have on learning. Online students complete these additional questions to assist in determining the effectiveness of online learning tools.

In addition to the internal project evaluation, Michigan Technological University Center for Teaching, Learning, and Faculty Development conducts independent, external evaluations of all courses related to the project. This formative and independent feedback assist the project team in determining which elements of the new courses are meeting objectives and which can be further improved to better meet student and workforce needs. For the outreach activities, such as Michigan Technological University Summer Youth Programs, external evaluators were participated in the evaluation.

\section{Course evaluation results}

The course survey using Survey Monkey has been conducted three times in the fall 2010, spring 2011, and fall 2011, respectively. The results of the general questions showed that most students had some knowledge of conventional and hybrid vehicle systems, and improved to full knowledge or working knowledge at the end of the semester. The students also had some knowledge of how the course content is applied to conventional and hybrid vehicle systems, which improved to working knowledge or full knowledge at the end of the semester.

For the course-based questions, students agreed or strongly agreed that the course sessions and exams contributed to the learning of the course materials. These students strongly agreed or agreed that the teaching methods and homework assignments contributed to the learning of the course materials. For those students who participated in a laboratory agreed that the experiments contributed to their learning of the course materials. Open-ended comments were generally very favorable.

Finally, for the program-based questions, the survey results in 2011 show that $32 \%$ of students that responded took the class by distance learning, with a higher number open to taking a future course by distance learning. It was also found that $59 \%$ of students took these courses because they were part of the graduate or undergraduate certificate in hybrid electric drive vehicle engineering, and $61 \%$ of students took these courses because they were part of the master's degree in hybrid electric drive vehicle engineering. After completing the course, $86 \%$ of students are now interested in the certificate and $64 \%$ are interested in the master's degree.

\section{Evaluation results of the outreach activities}

The interdisciplinary education program in HEV engineering at Michigan Technological University organizes outreach activities annually. In this paper, the evaluation results of one sample outreach program Michigan Technological University Summer Youth Program - Motor Sports, are presented. Michigan Tech's Department of Educational Opportunity organizes Summer Youth Program annually for students in grade 6-12. The program provides a variety of week-long intensive programs aimed at investigating and discovering careers in the areas of engineering, science \& technology, business, computing, outdoors \& environmental studies, and 
humanities \& social sciences. "Motor Sports" is one of such programs with a focus on hybrid and electrical vehicles. Figure 6 shows the demographics of the participants in summer 2011. A survey instrument was developed and distributed at the end of the "Motor Sports" program. Participation in the survey was voluntary. The questions on the survey and survey results, which were very positive, are summarized in Table $\mathrm{V}$.
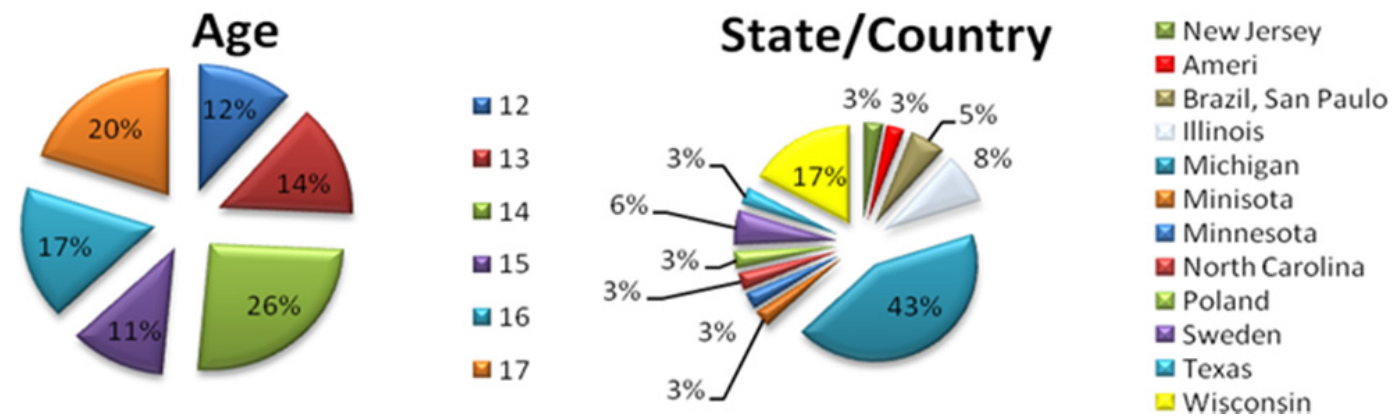

Figure 6. The demographics of the participants of the motor sports program.

TABLE V: SURVEY QUESTIONS AND RESULTS OF THE MOTOR SPORTS PROGRAM.

Q: What was your reasoning behind choosing your exploration?

$\begin{array}{lllll}70.27 \% \text { - I was } & 10.81 \%-\text { My friends } & \begin{array}{l}8.11 \%-\text { My parents } \\ \text { made me take this class }\end{array} & \begin{array}{l}2.70 \%-\text { My } \\ \text { guidance counselor }\end{array} & 8.11 \%-\text { Other }\end{array}$
the subject

Q: How would you rate the hands-on activities during your exploration? 45.71\% - Excellent 34.29\% - Good 5.71\% - Average 14.29\% - Fair

Q: How inspired are you to learn more about your exploration after attending the Summer Youth Program as a result of your experience here? $29.41 \%$ - Extremely $\quad 44.12 \%$ - Very $\quad 26.47 \%$ - Moderately

Q: If you received a scholarship, would you have attended the program if you had not received one? $24.24 \%$ - Yes $\quad 18.18 \%$ - No $\quad 57.58 \%-$ N/A

Q: Would you recommend your exploration to others? $94 \%$ - Yes

\section{Conclusions}

Michigan Technological University College of Engineering (COE) has over 3800 students enrolled in eight engineering departments. The Electric and Computer Engineering department has had a strong and continuous program in electrical power since its inception in the 1920s, with an established base of 14 undergraduate and graduate courses in this area. The COE currently offers undergraduate and graduate certificates in Advanced Electrical Power Engineering. The Mechanical Engineering department has been in the top 10 for BSME graduates nationwide for each of the last 27 years, with one of the department's leading educational and research areas being vehicle and propulsion systems. In the mid-1990's, Michigan Technological University was one of the first universities in the world to establish distance learning with programs designed specifically to support the automotive OEM's and the electric power industries. It has the experience, courses, and faculty necessary to deliver the education program simultaneously to students on, and off campus nationwide. As an example, 
the Advanced Propulsion for Hybrid Vehicles course was delivered in the first semester to 36 oncampus students and remotely to 56 engineering students with EE, ME and other backgrounds. The University and its faculty have strong ties to this industry through our educational and research programs.

Distinctively the focus of the education program is at the vehicle level and the interconnection to the electric grid. The vehicle level aspects of the program include vehicle requirements, integration of propulsion technologies, safety, diagnostics, control and calibration. Michigan Technological University and our industrial partners see these as critical limiting factors in the development and production of advanced electric transportation systems. Additionally, the effort leverages the existing distance learning program in electric power. The result are an interdisciplinary program that meets the needs of the transportation and power industries and provides students with a unique skill set that accelerate the advancement and development of electric drive vehicles. Our distance learning students come from both the transportation and electric power industries. We seek guidance from these industries to ensure that the program meets the needs of their work force with the course contents reviewed by topical industry experts. This education program will provide a supply of engineers to a significant and sustainable US job base.

\section{References}

1 M. Demere. "Top 10 Automotive Colleges and Universities in the U.S.". Available:

http:/www.edmunds.com/car-reviews/top-10/top-10-automotive-colleges-and-universities-in-the-us.html. [Accessed: January 8, 2012].

2 T. J. Hassell, A. M. Oliveira, and W. W. Weaver, "Control system development for undergraduate exposure," in ASEE/IEEE Frontiers in Education Conference, 2010, pp. 1-7.

3 M. P. S. Shengnan, and S. Rahman, "Challenges of PHEV penetration to the residential distribution network," in IEEE Power \& Energy Society General Meeting, 2009, pp. 1-8.

4 "Assessment of Technologies for Improving Light Duty Vehicle Fuel Economy," National Research Council ISBN: 978-0-309-15607-3, 2010. 